\title{
Quantitative analysis of mercury burden in waste water released from hospital in Jhansi, U.P.
}

\author{
Bhupinder Kaur ${ }^{1,}$, , Rishi Kumar Saxena ${ }^{1}$, Ranmeet Kaur ${ }^{2}$ \\ ${ }^{1}$ Department of Microbiology, Bundelkhand University, Jhansi, India \\ ${ }^{2}$ Department of Chemistry, D.A.V. College, Kanpur, India
}

Email address:

bhupinder2708@gmail.com (B. Kaur)

\section{To cite this article:}

Bhupinder Kaur, Rishi Kumar Saxena, Ranmeet Kaur. Quantitative Analysis of Mercury Burden in Waste Water Released from Hospital in Jhansi, U.P.. International Journal of Environmental Monitoring and Analysis. Vol. 2, No. 6, 2014, pp. 328-332.

doi: $10.11648 /$ j.ijema.20140206.15

\begin{abstract}
The sources of mercury in hospital wastewaters include potable water supply, medical equipment breakage, laboratory chemicals, medicinal wastes, amalgam from dental clinics, human amalgam and dietary waste retained in wastewater sumps and traps. Cleaning products used in hospitals may contain trace mercury levels from the caustic soda used in production of soap or from chemicals that may contain traces of mercury as an impurity. This Study assesses the mercury content in hospital waste water from the hospital in Jhansi City. Samples were collected from three different sites during different season and were analyzed quantitatively. The quantity of mercury ranged between $0.100 \mathrm{mg} / \mathrm{L} \mathrm{to} 0.150 \mathrm{mg} / \mathrm{L}$. the higher conc. is found in waste water samples collected from site $\mathrm{C}$ which is the disposal site of laboratory, radiology department, operation theatre etc. These finding are higher than agreeable limit of EPA which is $0.002 \mathrm{mg} / \mathrm{L}$. This indicates the contamination of receiving environment due to discharge of mercury in hospital waste water which could harm human and aquatic life. In this study in methods were used for reduction of mercury in hospital waste water. The sulfide precipitation reduced the quantity of mercury from $0.210 \mathrm{mg} / \mathrm{L}$ to $0.006 \mathrm{mg} / \mathrm{L}$. By using charcoal, it was found that mercury was reduced from $0.210 \mathrm{mg} / \mathrm{L}$ to $0.003 \mathrm{mg} / \mathrm{L}$.
\end{abstract}

Keywords: Hospital Waste Water, Mercury, EPA, Jhansi City

\section{Introduction}

The term heavy metal refers to any metallic chemical that has high relative density and is toxic or poisonous at low level. The heavy metals like cadmium, zinc, lead, mercury, silver, chromium etc. are non-degradable metals in the environment. Hospitals are one of the major sources of heavy metals in the environment. The United States recognizes health care facilities, through medical waste incineration, as the fourth largest source of mercury emissions to the atmosphere [1]. Hospitals are also recognized as a source of mercury discharge to the wastewater system. The Palo Alto (California) Regional Water Quality Control Plant has determined that mercury contributions from hospitals represent $4 \%$ of its total mercury loading [2]. Mercury is a persistent, bioaccumulative, and potent environmental neurotoxin and is toxic at very low concentrations. It is found in many common health care devices, including thermometers, blood pressure cuffs, laboratory chemicals, measurement devices, fixatives, and cleaning supplies. Mercury from medical equipment may enter wastewater if mercury from broken equipment is discharged to sinks and drains [3]. Products entering hospital wastewater as an active ingredient, a contaminated ingredient or a preservative include: laboratory chemicals, medicinal wastes, amalgam from dental clinics, human amalgam and dietary waste and cleaning products. Dirt and dye from laundry processing, and mercury settled in wastewater sumps and traps can also be mercury sources. Mercury-containing wastes disposed down the drain can pass through the wastewater treatment system and into the rivers, where it gets concentrated in the sediments and bioaccumulate in aquatic animals. Domestic wastewater and municipal wastewater treatment plants account for less than 1 percent of the total mercury entering the environment [4]. The largest sources of mercury to Publicly Owned Treatment Works (POTWs) include discharges from dental offices $(\sim 36$ percent relative contribution of mercury influent load), domestic sources (human wastes, household products and laundry graywater; 
20 percent relative contribution of mercury influent load) and hospitals $(\sim 8$ percent relative contribution of mercury influent load) [5]. Household washing product contribution to the net mercury load to municipal wastewater has been reported as 0.5 percent or less[6].

The production, use, release and disposal of heavy metals like mercury is well characterized and risk of exposure for general population is potentially high. The use of mercury leads to a high risk of their release to the environment, particularly to water. Numerous processes exist for removal of dissolved heavy metals including-ion exchange, precipitation, phytoextraction, ultrafilteration, reverse osmosis and electrodialysis. [7-10]. Chemical precipitation is the most common technique used for treatment of metal containing waste water [11-13]. Several precipitation methods are used for removing heavy metals and all operate under same fundamental principle in which soluble metals are converted to relatively insoluble metal salts (precipitation) by adding precipitating agents.

Increased understanding and concerns about the effects of mercury exposure on both human health and aquatic life have led to the development of water and fish tissue criteria for protecting human health and aquatic species.

Concern over mercury in environment arises from the extremely toxic forms in which mercury can be a threat to public safety. Mercury poisoning is associated with tremor, brain damage and damage to nervous system if exposed to humans.

This study aims at presenting the data for quantitative analysis of mercury in hospital waste water and experiments were planned to reduce its quantity so that its value is reduced to acceptable limits of discharge.

\section{Materials and Methods}

\subsection{Sample Collection}

Samples of waste water were collected from three different sampling sites - Site A where the entire waste water from the hospital was being disposed off. Site B was the site where waste water flows out through the inhabitant of indoor patients. The site $\mathrm{C}$ was the site where waste water was passed out from various laboratories such as pathology, radiology laboratory etc. Samples were collected from each site in $250 \mathrm{ml}$ pre-sterilized glass bottles and transported to laboratory in a cooler and stored at $4^{0} \mathrm{C}$ in chiller.

\subsection{Analytical Methods}

The mercury is detected in two steps Spot Test Analysis and Volumetric Analysis. For Spot Test Analysis Diphenyl Carbazone Reagent is used. It is a $1 \%$ alcoholic solution. A drop of test sample and drop of $0.2 \mathrm{~N}$ - nitric acid on was placed on filter paper moistened with freshly prepared reagent. A violet or blue colour obtained. It indicated the presence of mercury. Another reagent Stannous Chloride is used for spot test analysis. This is a 5\% solution of stannous chloride in $10 \mathrm{~N}$ hydrochloric acid. Drop of sample solution was added to the filter paper having a drop of reagent. A brown or black stain of mercury confirmed its presence.

For Volumetric Analysis [14] mercury is first precipitated as mercurous ions according to following reaction.

$$
2 \mathrm{HgCl}_{2}+\mathrm{H}_{3} \mathrm{PO}_{3}+\mathrm{H}_{2} \mathrm{O} \rightarrow \mathrm{Hg}_{2} \mathrm{Cl}_{2}+2 \mathrm{HCl}+\mathrm{H}_{3} \mathrm{PO}_{4}
$$

The reagents used were $1 \mathrm{~N}$ hydrochloric acid $(\mathrm{HCl}), 50 \%$ phosphorus acid solution $\left(\mathrm{H}_{3} \mathrm{PO}_{3}\right)$, Concentrated hydrochloric acid $(\mathrm{HCl})$, Carbon tetra chloride solution $\left(\mathrm{CCl}_{4}\right), 0.025 \mathrm{M}$ potassium iodate solution $\left(\mathrm{KIO}_{3}\right)$.

$25 \mathrm{ml}$ of sample was taken in conical flask and $25 \mathrm{ml}$ of water, $2 \mathrm{ml}$ of $1 \mathrm{~N} \mathrm{HCl}$ and excess of $50 \% \mathrm{H}_{3} \mathrm{PO}_{3}$ was added and stirred thoroughly. The flask was then allowed to stand for $12 \mathrm{hrs}$. The precipitation of $\mathrm{Hg}_{2} \mathrm{Cl}_{2}$ was filtered through a filter paper and washed moderately with cold water. The precipitation was transferred from filter paper to a $250 \mathrm{ml}$ reagent bottle. $30 \mathrm{ml}$ of concentrated $\mathrm{HCl}, 20 \mathrm{ml}$ of distilled water and $5 \mathrm{ml}$ of $\mathrm{CCl}_{4}$ was added to reagent bottle. The mixture was titrated with standard $0.025 \mathrm{M} \mathrm{KIO}_{3}$ solution. After titration the amount of mercury was calculated in the sample according equation -

$$
\begin{gathered}
\mathrm{IO}_{3}{ }^{-}+2 \mathrm{Hg}_{2} \mathrm{Cl}_{2}+6 \mathrm{H}+13 \mathrm{Cl}^{-}=\mathrm{ICl}+4\left[\mathrm{HgCl}_{4}\right]^{-}+3 \mathrm{H}_{2} \mathrm{O} \\
\text { Thus } \mathrm{KIO}_{3}=4 \mathrm{Hg}=2 \mathrm{Hg}_{2} \mathrm{Cl}_{2} \text { and } \\
1 \mathrm{ml} 0.025 \mathrm{M} \mathrm{KIO}_{3}=0.02006 \mathrm{~g} \mathrm{Hg}=0.02361 \mathrm{gHg}_{2} \mathrm{Cl}_{2}
\end{gathered}
$$

Equation states that 4 mole of $\mathrm{Hg}^{+}$ions react with 1 mole of $\mathrm{KIO}_{3}$. By calculating the moles of $\mathrm{KIO}_{3}$ used in titration, the moles of mercury $\left(\mathrm{Hg}^{+}\right)$can be calculated.

\subsection{Removal of Mercury}

The experiments were planned to reduce the mercury in quantity so that it could be within acceptable limits. The methods used for reduction of mercury were based on the quantity of the effluent passing out of the hospital and at the same time keeping in mid: (1) The capital operating costs should be low, (2) The removal should be efficient and high with very little disadvantages. Two methods were used for removal of mercury - Sulfide precipitation and using activated charcoal.

\subsubsection{Sulfide Precipitation}

In sulfide precipitation method $1000 \mathrm{ml}$ of sample was taken in reaction vessel. Sodium sulfide was then added to the waste water samples where the soluble mercury was precipitated as mercury sulfide. Then precipitate was separated from samples by filteration. Filterate was centrifuged at $4000 \mathrm{rpm}$ and then filtrate was analysed for the quantity of these metals after treatment.

\subsubsection{Using Activated Charcoal}

In this method activated charcoal column was prepared by using sterilized burette. Glass burette with glass stopper at lower end was taken. First, glass beads were placed upto a height of $5 \mathrm{~cm}$. Above the glass beads, activated charcoal was placed upto a height of $7 \mathrm{~cm}$. Lower end of burette was fitted 
in sterilized collection glass bottle using a rubber cork. Into another hole of rubber cork twice bent glass tube was introduced. Other end of bent tube was introduced in another bottle with rubber cork. Care was taken so that the end of bent rod in the bottle must be immersed in sterilized water so that no external air could enter in the bottle. The waste water sample was poured into the burette and was plugged at open end through sterilized cotton. After some time the water sample passed through activated charcoal and collected in the lower bottle. After recovery the waste sample was analysed for mercury.

\section{Result}

The heavy metal mercury was quantitatively analysed in the samples collected from all the three sites of hospital. Mercury was measured by volumetric method [Table-I] During winter season, the samples collected from site A showed $0.132 \mathrm{mg} / \mathrm{L}$ of mercury. Sample collected from site B showed $0.100 \mathrm{mg} / \mathrm{L}$ of mercury, while at site $\mathrm{C}$, mercury was equivalent to 0.160 $\mathrm{mg} / \mathrm{L}$. During summer season, at Site A, mercury was equivalent to $0.150 \mathrm{mg} / \mathrm{L}$ while. At site $\mathrm{B}$ the sample collected showed $0.120 \mathrm{mg} / \mathrm{L}$ of mercury, while at Site C, mercury was $0.210 \mathrm{mg} / \mathrm{L}$. in rainy season, at site A the mercury was 0.145 $\mathrm{mg} / \mathrm{L}$. At site B, the mercury was $0.100 \mathrm{mg} / \mathrm{L}$ and at Site C, the mercury was $0.176 \mathrm{mg} / \mathrm{L}$. From these observations, it is concluded that mercury was higher in summer season as compared to rainy and winter season at all the three sites. The lowest quantity of mercury was found in winter season.

Table I. Mercury Detected in Hospital Waste Water Samples of Three Sampling Sites $(\mathrm{mg} / \mathrm{L})$

\begin{tabular}{lccc}
\hline Season & Site A & Site B & Site C \\
\hline Winter & 0.132 & 0.100 & 0.160 \\
Summer & 0.150 & 0.120 & 0.210 \\
Rainy & 0.145 & 0.100 & 0.176 \\
\hline
\end{tabular}

All Reading are mean of triplet sample reading.

To reduce the quantity of mercury in hospital waste water samples, two methods were used as mentioned earlier [Table-II]. The sulfide precipitation reduced the quantity of mercury from $0.210 \mathrm{mg} / \mathrm{L}$ to $0.006 \mathrm{mg} / \mathrm{L}$. This value is quite low and very near to the agreeable limit of EPA.

Table II. Reduction of Mercury in hospital waste water samples at site C during summer season $(\mathrm{mg} / \mathrm{L})$

\begin{tabular}{llll}
\hline Method & Initial Conc. & $\begin{array}{l}\text { Conc. After } \\
\text { treatment }\end{array}$ & $\begin{array}{l}\text { Agreeable limit of } \\
\text { discharge by EPA }\end{array}$ \\
\hline $\begin{array}{l}\text { Sulfide } \\
\text { Precipitation }\end{array}$ & 0.210 & 0.006 & 0.002 \\
$\begin{array}{l}\text { Activated } \\
\text { Charcoal } \\
\text { Method }\end{array}$ & 0.210 & 0.003 & 0.002 \\
\hline
\end{tabular}

All Reading are mean of triplet sample reading.

By using activated charcoal, it was found that mercury was reduced from $0.210 \mathrm{mg} / \mathrm{L}$ to $0.003 \mathrm{mg} / \mathrm{L}$. The agreeable limit of EPA is $0.002 \mathrm{mg} / \mathrm{L}$. Quantitative estimation of mercury was done with the help of micro-balance which meets the requirement for measuring small masses with high readability. Its measurement range is $0.1 \mu \mathrm{g}$ to $2 \mathrm{~g}$.

\section{Discussion}

Mercury is persistant, toxic, bioaccumulative substance that possess serious health risk to human and animals. Health care facilities use variety of products that contain mercury. Mercury is used in thermometers, blood pressure cuffs, batteries, many drugs etc. Mercury containing fixatives are commonly used in histopathology laboratories. Mercury is released from hospital by incineration of medical waste and release of mercury containing chemicals into waste water. Twenty percent of the spilled mercury from fever thermometers is reportedly discharged to wastewater when the spill is cleaned up by washing the area; ten percent of the spilled mercury is lost through volatilization[15].

Over 50 percent of hospital sphygmomanometers are reported to leak mercury [16]. Spill incidents are reported at approximately 9.0 kilograms $(\mathrm{kg})$ of mercury spilled per hospital per year [17]. The mass of mercury entering hospital wastewater from this source depends on spill response procedures, but if estimated at 20 percent of the spilled mercury [15], this source contributes approximately $0.06 \mathrm{~kg}$ to $1.8 \mathrm{~kg}$ of mercury/hospital/year. Despite the introduction of new types of materials, dental amalgam, which contains approximately 50 percent mercury by weight, is the most popular material used for restoring teeth [18]. The average human excretion of mercury from amalgam-filled teeth is estimated to range between 17.2 and $67 \mu \mathrm{g} /$ person/day [19].

Two commonly used formulations of mercuric chloride fixatives used in histopathology laboratories are Zenker's Fluid and B5 Solution [20]. Zenker's Fluid is reported to contain mercury at 37.5 grams per liter $(\mathrm{g} / \mathrm{L})$ [21] and B5 Solution is reported to contain $148.4 \mu \mathrm{g} / \mathrm{L}$ [22]. The supernatant from using B5 solution that could be discharged to wastewater was reported to contain $25 \mathrm{mg} / \mathrm{L}$ and $260 \mathrm{mg} / \mathrm{L}$ of mercury on two separate occasions [20]. The mass of mercury entering hospital waste water from laboratory chemical products will depend on the quantity and type of chemical products disposed with hospital waste water.

In health care facilities, the cleaning of surfaces is important for infection control and basic sanitation. The concentrations of mercury in laundry detergents have been reported to range from $1.478 \mu \mathrm{g} / \mathrm{kg}$ [19] to less than $25 \mu \mathrm{g} / \mathrm{kg}$ [23]. Washing products include products used for personal hygiene, such as soap, shampoo and dishwashing detergents. The reported concentrations of mercury in soap range from approximately $0.0027 \mu \mathrm{g} / \mathrm{kg}$ [24] to $7.908 \mu \mathrm{g} / \mathrm{kg}$ [19]. All these cleaning products contribute mercury in hospital waste water.

In 2001 the Nova Scotia Department of Environment and Laboratory partnered with USEPA, Environment Canada to conduct a study to determine mercury used and released in 17 Nova Scotia Hospitals. Total mercury concentration in hospital waste water ranged from 0.0064 to $0.26 \mu \mathrm{g} / \mathrm{L}$ with 
mean concentration $0.10 \mu \mathrm{g} / \mathrm{L}$. These findings are less than the quantity found in present study. It appears that in Canada they must be taking some precautions so that these substances may not enter the waste water system.

Mercury is a toxic pollutant and is listed as one of 12 priority chemicals by the EPA Persistent, Bioaccumulative, and Toxic (PBT) Chemical Program. Consuming fish from mercury-polluted water bodies can severely affect the central nervous system; impair hearing, speech and gait; and cause blindness, tremors, insomnia, emotional instability, paralysis, loss of muscular control, and even death. For treatment of waste water sulfide precipitation effectively removes mercury [25]. The insoluble sulfide precipitate first patented as 'sulfex' process [26] which removes dissolved metal by mixing the waste water with iron sulfide slurry in a solid/liquid contant chamber. In this study sulfide precipitation method remove the mercury from $0.201 \mathrm{mg} / \mathrm{L}$ to $0.006 \mathrm{mg} / \mathrm{L}$. This value is quite low and very near agreeable limit of EPA. Activated carbon adsorption is considered to be particularly competitive and effective process for removal of heavy metals at trace quantities [27]. Granulated activated carbon (GAC) removed $99.8 \%$ of the mercury in the waste water. Many worker conducted lab work to investigate the feasibility of using activated carbon for mercury removal from aqueous wastes [28]. The activated charcoal reduced the mercury $0.210 \mathrm{mg} / \mathrm{L}$ to $0.003 \mathrm{mg} / \mathrm{L}$. This is again near to agreeable limit of EPA $(0.002 \mathrm{mg} / \mathrm{L})$.

\section{Conclusion}

Although mercury is found in many places within hospitals, a mercury elimination plan should include a prioritized list of targets. Hospitals most frequently commit to becoming mercury-free based on an ethical motivation to protect human health and the environment. The waste water should be discharged to the municipal sewer system with proper treatment. This study concludes that waste water released from hospital is loaded with high amount of mercury. If hospital effluent discharged into the natural environment without proper treatment then this can create biological imbalance and at the same time cause health hazards. Therefore, efficient treatment of hospital waste water should be conducted. A switch to mercury free alternatives can save a hospital potential regulatory and disposal costs. Most mercury-containing equipment have a mercury-free alternative. Although some mercury-free alternatives may initially cost more, facilities often find that their initial capital costs are outweighed by the total costs associated with mercury cleanup equipment, spill costs and liabilities, and handling and disposal costs and liabilities.

\section{References}

[1] Executive summary. In: Mercury Study Report to Congress. Vol. 1. Washington: Environmental Protection Agency (US), Office of Air Quality Planning \& Standards and Office of
Research and Development; 1997. Pub.No.: EPA-452/R-97-003.

[2] Larry Walker Associates. Mercury pollution prevention. Palo Alto (CA): Palo Alto Regional Water Quality Authority; 1997 Oct.

[3] Kameyama, K. (1992) Reducing Mercury Wastes at Hospitals. Water Environment and Technology, 4(5): p. 70-72.

[4] Association of Metropolitan Sewerage Agencies, Household Mercury Poses National Clean Water Compliance Concerns. Accessed February 27, 2003. http://www.amsacleanwater. org/advocacy/releases/82200.cfm

[5] Walker, L.(2000) Mercury Source Control and Pollution Prevention Program Evaluation. Larry Walker and Associates, 1-57. http://www.amsacleanwater. org/advocacy/mercgrant/finalrepor.pdf

[6] Jenkins, D. and Russell, L.L. (1994) The Heavy Metals Contribution of Household Washing Products to Heavy Metals in Wastewater. Water Environmental Research, 66: p.805.

[7] Appegate, L.E. (1984) Membrane Separation Processes, Excerpted by special permission from Chemical Engineering 91,64. Copyright 1984 by Mc. Graw Hill,Inc,N.Y.10020.

[8] Geselbarcht, J.( 1996) Micro Filtration/Reverse osmosis pilot trials for Livermore, California, Advanced Water Reclamation, in: 1996 Water Reuse Conference Proceedings, AWWA, p. 187.

[9] Schnoor, J. L. (1997) Phytore-mediation TE- 97-01, Ground water Remediation technologies, analysis centre, Pittsburgh.

[10] Sengupta, A. K. and Clifford, D. (1986) Environ. Sci. Technol. $20,149$.

[11] EPA 625/8-80-003 Summary report 1980 control and treatment technology for the Metal Finishing Industry; Sulfide Precipitation, Technology Transfer Division, Washington, D.C.

[12] Patterson, J.W. and Minear, R. N. (1975) Physical - chemical methods of Heavy metals removal. In heavy metals in the Aquatic Environment (P.A. Krenkel, ed.), pp. 261-276. Oxford, England: Pergamon Press.

[13] Peters, R.W., Ku, Y. and Bhattacharya, D.(1985) Evaluation of Recent Treatment Techniques for removal of heavy metals from industrial waste waters. AICHE Symposium Series, Separation of Heavy metals and other contaminants, 81 (243) : 165-203.

[14] Jeffery, G.H., Bassett, J., Mendham, J. and Denny, R. C.(1989) Vogel's Textbook of Quantitative Chemical Analysis, $5^{\text {th }}$ ed. Longman, New York.

[15] Barr Engineering, Substance Flow Analysis of Mercury in Products. 2001, Barr Engineering, 4700 77th Street, Minneapolis, MN 55435, USA, p. 91. http://www.pca.state.mn.us/ publications/hg-substance.pdf.

[16] Colquitt, P.J. (1995) The Effect of Mercury Vapor Exposure on the Fertility of Female Dental Assistants [letter]. Occupational Environmental Medicine,52: p.21.

[17] Colquitt, P.J. (1999) Will the Millimeter of Mercury be Replaced by the Kilopascal? Journal of Hypertension, 17: p. 305-306.

[18] Clarkson, T.W. (2002) The Three Modern Faces of Mercury. Environmental Health Perspectives, .110(1): p.11-23. 
[19] Association of Metropolitan Sewerage Agencies, Evaluation of Domestic Sources of Mercury. Washington, DC 2000, pp. 9 10, 12, Table 5, Table 6. http://www.amsacleanwater. org/pubs/mercury/mercury.pdf

[20] Harvie, J. (1997) Eliminating Mercury Use in Hospital Laboratories. A Step Towards Zero Discharge. Public Health Reports, 114: p.353-358.

[21] Nalle, C. Personal Communication, 14/15/03. EIP Associates. 601 Montgomery Street, Suite 500, San Francisco, California 94111.

[22] MASCO, Mercury Database, Medical Academic and Scientific Community Organization, Inc. http://www1.netcasters.com/mercury/.

[23] Jenkins, D. (1998) The Effect of Reformulation of Household Powder Laundry Detergents on Their contribution to Heavy Metals in Wastewater. Water Environmental Research, 70(5): p. $980-983$.
[24] EPA, DRAFT Wisconsin Mercury Sourcebook: Hospitals, Wiscosin Department of Natural Resources, http://www.epa.gov/glnpo/bnsdocs/ hgsbook/hospital.pdf.

[25] Technical Resource Document, Treatment Technologies for Metal/Cyanide-containing Wastes. (EPA 1987) Hazardous Waste Engineering Research Laboratory, NTIS Order number PB 38-143896

[26] Scott, M.C. (1979) An EPA Demonstration Plant for Heavy metals removal by sulfide precipitation. In Proc. $2^{\text {nd }}$ conference Advanced Pollution control for Metal finishing industry.

[27] Huang, C.P. and Blankenship, D.W. ( 1984) The removal of mercury (II) from dilute aqueous solution by activated carbon. Water Res. 18(1):3746.

[28] Gates, D. D., Chao, K. K., and Cameron, P. A.(1995) Mercury removal from liquid and solid mixed wastes. Presented at 1995 waste management conference, $\mathrm{Tu}$ cson, Arizone (February 26- March 2,1996). 